\title{
Isolation of items and the stimulus suffix effect*
}

\author{
DAVID G. ELMES \\ Washington and Lee University, Lexington, Virginia 24450
}

\begin{abstract}
Thirty Ss heard and serially recalled 36 different nine-digit series. The recall cue was a buzzer, the word zero read in the same voice that read the first seven digits, or the word zero read in a voice different from the one that read the first seven digits. In half the series, all nine digits were read in the same voice. The final two digits of the remaining series were isolated by having them read in a voice different from the one that read the first seven digits. Zero suffixes disrupted recall of the terminal digits more than the buzzer (the stimulus suffix effect) and had a greater degrading effect when they were in the same voice as the final two digits than when the zero suffixes and the final digits were read in different voices. Isolated digits were more likely to be recalled than nonisolated digits. Results suggest the importance of perceptual analysis in both the stimulus suffix effect and the isolation effect.
\end{abstract}

Precategorical acoustic storage (PAS) is a brief storage system that Crowder and Morton (1969) proposed to account for the superiority of immediate recall following auditory as opposed to visual presentation. With serial recall, the superiority of auditory presentation is specific to the last few serial positions, and it is these late-list items that are presumed to be held in PAS.

Several properties of PAS have been determined by use of the stimulus-suffix paradigm (e.g., Crowder, 1971; Morton, Crowder, \& Prussin, 1971). The suffix is a redundant element (usually the word zero) that serves as a recall cue for a list of auditorially presented digits but does not itself have to be recalled. Compared to immediate serial recall following a buzzer or tone cue, memory for the final few digits is impaired following a zero suffix. Results of an extensive series of studies by Crowder and his associates reveal the following characteristics (among others) of PAS: (a) the effective duration of information in PAS is about $2 \mathrm{sec}$ (Crowder, $1969 ; 1971$ ); (b) variations in meaning, emotionality, and frequency of occurrence of the suffix do not change its effectiveness (Crowder \& Raeburn, 1970; Morton et al, 1971); (c) and the acoustic properties of the zero suffix (e.g., pitch, timbre, or localization) do determine its effectiveness (Morton et al, 1971). Findings $b$ and $c$ are believed to provide strong evidence for the precategorical nature of information in PAS.

The present experiment is primarily concerned with the question of why speech (e.g., the word zero) and nonspeech (e.g., a tone or a buzzer) suffixes have differential capabilities for degrading digits already in PAS. Crowder (1971) has distinguished between two possibilities: a structural theory and an attentional theory. According to the structural view, inputs as disparate in their auditory characteristics as a buzzer and the word zero enter into different parts of PAS so that a

\footnotetext{
*This research was supported by a Robert E. Lee Research Grant. The assistance of John C. Dovel in collecting and analyzing the data is gratefully acknowledged. Requests for reprints should be sent to David G. Elmes, Department of Psychology, Washington and Lee University, Lexington, Virginia 24450.
}

buzzer is not an effective suffix because it is located apart from the digits in PAS. The attentional view holds that discriminations among basic acoustical features determine what actually enters PAS and the extent of entry. A zero, because it is a speech signal, is more likely than a buzzer to enter PAS completely and thus is more likely to degrade the digits already in PAS. As Crowder (1971) pointed out, these two theories resemble those postulated to account for data derived from studies of selective attention and multichannel listening (e.g., Moray, 1969; Norman, 1969). The structural theory is a theory of hearing different inputs, while the attentional hypothesis represents a theory of listening to or analyzing incoming information.

The evidence that exists supports the idea that attentional mechanisms are important in the functioning of PAS. For example, Morton et al (1971) have shown that localization of the suffix is important in determining its effect, and this localization result must take place following some selection (attention) process. In addition, Morton et al reported that a zero suffix in a voice different from the voice that read the digits degrades recall of the final two digits less than a zero suffix that is in the same voice as the digit series. The unelaborated structural position implies that speech signals of the same class should be heard to the same extent and thus should have similar degrading effects. Since this is not the case, as Morton et al have shown in regard to speech localization and voice quality, it appears that the viability of information in PAS is more likely to be related to attentional mechanisms than to structural factors. Events that share many acoustical features (e.g., localization or voice quality) enter PAS to the same extent and may interfere with each other, whereas suffixes of different voice quality or localization will not degrade the digits as much as similarly voiced or localized suffixes.

The present study sought to verify and extend the suffix-voice results of Morton et al by varying both the voice of the suffix and the voice of the final two digits. For the reasons mentioned above, the structural theory predicts minimal effects of voice quality. On the other 
Table 1

Mean Total Errors Per S (SD in Parentheses)

\begin{tabular}{|c|c|c|c|c|}
\hline \multirow[b]{2}{*}{ Condition } & \multicolumn{3}{|c|}{ Suffix Type } & \multirow[b]{2}{*}{ Mean } \\
\hline & Buzzer & $\begin{array}{l}\text { Zero } \\
\text { Same }\end{array}$ & $\begin{array}{c}\text { Zero } \\
\text { Different }\end{array}$ & \\
\hline Isolation & $\begin{array}{l}17.1 \\
(6.1)\end{array}$ & $\begin{array}{l}19.3 \\
(6.7)\end{array}$ & $\begin{array}{l}21.7 \\
(7.3)\end{array}$ & 19.3 \\
\hline Nonisolation & $\begin{array}{l}18.9 \\
(6.5)\end{array}$ & $\begin{array}{l}24.9 \\
(8.2)\end{array}$ & $\begin{array}{l}21.2 \\
(7.3)\end{array}$ & 21.7 \\
\hline Mean & 18.0 & 22.1 & 21.4 & \\
\hline
\end{tabular}

hand, it follows from the attentional position that the acoustical features shared by the digits and the speech (zero) suffix are of utmost importance: when the digits and the zero suffix occur in the same voice, there should be a greater decrement in recall than when the digits and the suffix are presented in different voices.

In some of the lists of the present experiment, the final two digits were isolated from the remainder by presenting them in a voice different from the one that read the first seven. According to the structural theory, there should be little, if any, effect of isolation. If the reasoning behind the attentional theory is sound, then recall should be higher for isolated as opposed to nonisolated digits. The isolated digits should enter PAS to a different extent than nonisolated digits and should be less susceptible than nonisolated digits to the degrading effects of the suffix and other digits in PAS. To complete the test of the attentional position, some of the series had a suffix in the same voice as the isolated digits, wherein recall of the isolated digits should be poorer than when the isolated digits and the suffix occur in different voices.

The present results should provide data relevant to both the stimulus suffix effect and the von Restorff isolation effect.

\section{METHOD}

\section{Subjects}

The 30 Washington and Lee University students, naive to serial recall laboratory tasks, were tested in small groups.

\section{Design}

The design can be considered a 3 by 2 within-S design. There were three different suffixes: a buzzer, a zero in the same voice as the majority of the message, and a zero in a voice different from the majority of the message. The final two digits of the series were either read in the same voice as the rest of the message or they were read in a different voice. Each list contained nine digits, and there were six repetitions of each condition.

\section{Materials and Apparatus}

Thirty-six series of the digits 1-9 were recorded on magnetic tape at a rate of 2 digits $/ \mathrm{sec}$. All suffixes occurred $.5 \mathrm{sec}$ after the final item of the series. Position of the digits within a series was random with the restriction that runs of consecutive numbers of three or more were avoided. Each $S$ heard the same 36 sequences of digits in the same order, but the conditions were assigned to series in three different orders. The first seven digits of every series were read by the same male voice, as were the last two digits in the nonisolation condition. In half the series, the last two digits were isolated by having them read by a female voice that was discriminably different from the male voice. These same voices also read the zero suffixes in the appropriate conditions. The factorial combination of suffix voice and final digit voice resulted in conditions in which the isolated digits and the suffix occurred in the same or different voice, and the nonisolated digit series also had zero suffixes in the same or different voice. ${ }^{1}$ In the control conditions, a buzzer served as the recall cue. An attempt was made to equate the loudness and duration of the buzzer to the loudness and duration of the zero suffixes.

\section{Procedure}

Each S heard and serially recalled the same 36 lists in the same order. In each block of six series, each of the six conditions occurred once, and assignment of conditions to position in the blocks was according to a balanced Latin square. Three different assignments of conditions to the 36 lists assured that there were 18 different series in each condition and that particular series were partially balanced across conditions. The three different assignments of conditions to series were heard by $10 \mathrm{Ss}$ each. Written serial recall of each series within $30 \mathrm{sec}$ after presentation was on response sheets that contained nine spaces for each series. Instructions were for serial recall, and Ss were told that the zero at the end of the series was a recall cue and was not to be written down. The Ss were warned in advance that the recall cue would be either a buzzer or a zero, but they were not told that different voices would be used.

\section{RESULTS}

The mean total numbers of errors per $S$ in each condition summed across serial positions and repetitions appear in Table 1. Since each cell mean represents the mean numbers of errors per $S$ out of 54 possible (6 repetitions by 9 serial positions), the mean proportions of errors in each condition range from .31 to .46 . For purposes of explication, zero same refers to the condition in which the zero was in the same voice as the voice that read the first seven digits. Zero different designates the condition where the voice that read the zero suffix was different from the voice that read the first seven digits in each series. Therefore, when the last two digits were isolated in the zero different condition, the zero suffix and the final two digits were read in the same voice.

Fewer errors occurred when there was a buzzer recall cue $(\overline{\mathrm{X}}=18.0)$ than in the zero same $(\overline{\mathrm{X}}=22.1)$ and zero different $(\overline{\mathrm{X}}=21.4)$ conditions, $\mathrm{F}(2,58)=15.36$, $\mathrm{p}<.001$. In addition, fewer errors occurred when the last two digits were isolated $(\bar{X}=19.3)$ than when they were not isolated $(\overline{\mathrm{X}}=21.7), \mathrm{F}(1,29)=7.33, \mathrm{p}<.025$. As is apparent in Table 1 , recall in the isolated and nonisolated conditions was differentially influenced by the type of suffix, $F(2,58)=7.96, p<.005$.

The nature of the above effects can be seen more clearly in the normalized serial position curves (based on percent total errors) that appear in Fig. 1. Each data 
point is based on 180 observations ( 30 Ss by 6 repetitions). A significant Isolation-No Isolation by Serial Position interaction, $F(8,232)=22.22, p<.001$, resulted from both the different general shape of the curves in the two isolation conditions and the lower proportion of errors on the eighth item in the isolation condition than in the no isolation condition. Suffix type also interacted with serial position, $F(16,464)=2.50$, $\mathrm{p}<.005$, which resulted from the primary influence of suffix type on error rate in the final two serial positions. In addition, a significant three-way interaction, $F(16,464)=1.69, p<.05$, indicates that the opposite effects of the two different zero suffixes on isolated and nonisolated recall were limited primarily to the final two serial positions.

Further analysis by multiple comparisons of percent total errors in the final two serial positions was done with two-tailed Wilcoxon or Friedman tests. At both the eighth and ninth serial positions, fewer percent total errors occurred in the isolation than in the no isolation condition. For the isolated series, the three suffixes had significantly different effects on recall of the last item $(p<.05)$ and nearly reliable effects on the recall of the eighth item $(p<.10)$. Recall of the eighth item in nonisolated series did not differ in the different suffix conditions, but the suffixes did differentially influence recall of the ninth nonisolated item $(p<.001)$.

Inspection of the data revealed a reduction in errors across blocks. This decrease in errors was approximately the same in all conditions.

\section{DISCUSSION}

The present results have implications both for the functioning of PAS and for the mechanism(s) involved in the von Restorff isolation effect.

It would appear from the present results that the differential capabilities of speech and nonspeech sounds in degrading information in PAS are attributable to attentional mechanisms and not to structural factors. The version of structural theory presented by Crowder (1971) seems to require the same degrading effect from all speech suffixes regardless of voice quality, as well as the same level of digit recall regardless of voice quality. The structural theory predicts only that speech and nonspeech sounds will be differentially effective as suffixes. The attentional theory (Crowder, 1971), on the other hand, holds that the viability of information in PAS follows or is determined by perceptual analysis of the incoming information. Buzzers are not analyzed in the same way that a speech sound such as zero is analyzed; hence, the zero is more likely than the buzzer to degrade the other speech sounds in PAS. The deciding feature in favor of the attentional theory over the structural one is that the attentional position allows for acoustical discriminations among speech sounds that belong to the same generic class (e.g., the word zero read by different voices), whereas the structural position does

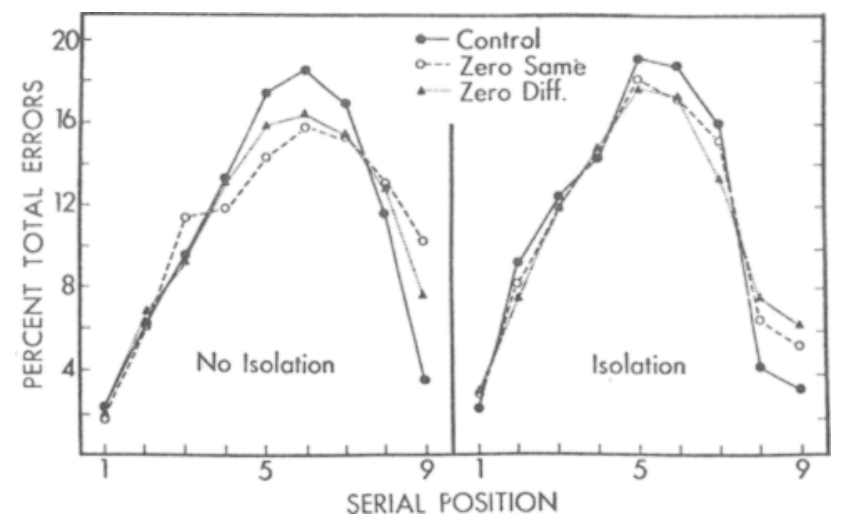

Fig. 1. Percent total errors as a function of serial position for all six conditions.

not. Speech sounds read by different voices (voices may differ in timbre and pitch as well as along subtle temporal dimensions) receive different analyses and are less likely to degrade each other in PAS than are acoustically similar events (consult Crowder, 1971, for some of the factors presumed to be involved in forgetting information in PAS).

As the present results indicate, in agreement with Morton et al (1971), zero suffixes that share the same voice quality with the final digits of a series have a greater degrading effect than suffixes that are in a voice different from the voice that read the final items. The isolated digits, because they were read in a different voice, received a different perceptual analysis than did the nonisolated digits; hence, the isolated items were less likely to be degraded by other digits and were more likely to be recalled than nonisolated items.

The present results taken in conjunction with those of Morton et al (1971) indicate that attentional mechanisms of the kind outlined above are important in determining the functioning of PAS. The attentional notion described here resembles theories that have gained favor as descriptions of performance in selective listening and divided attention tasks (e.g., Moray, 1969; Norman, 1969).

Attributing the higher recall of isolated as compared to nonisolated digits to differential perceptual processes appears compatible with a Gestalt interpretation of the von Restorff isolation effect (see Wallace, 1965). This perceptual interpretation and the fact that overall recall was higher from isolated series than from nonisolated series seem contrary to the notion that the isciation effect results from isolated events receiving rehearsal io the detriment of nonisolated events - imbalo, 1970; Elmes, Sanders, \& Dovel, 1973; Vaugh, 1969). If, however, memory is viewed as invoiving various levels of perceptual processing (Cermak, 1972; Craik \& Lockhart, 1972; Massaro, 1970), then th apparent contradiction between the present formation and the rehearsal account of the isolation fect may be eliminated. It seems reasonable to stippose that, because isolated 
events are less likely to be degraded than nonisolated events at a precategorical level (precategorical "storage" may be better labeled precategorical "processing"), the isolated items will be more available for further processing and rehearsal than nonisolated items. Differential rehearsal should be more in evidence than perceptual effects in those situations where the functioning of precategorical analysis has been superceded: for example, (a) in immediate memory tasks where presentation rate is slower than in the usual suffix study (e.g., Cimbalo, 1970); (b) in long-term memory tasks where long lists of words are presented (Waugh, 1969); (c) in long-term memory tasks where features of item presentation, such as massed vs distributed practice, permit Ss to rehearse items differentially (Elmes et al, 1973); or (d) when the material is amenable to deep (e.g., semantic) processing (Craik \& Lockhart, 1972). The present argument suggests that the von Restorff isolation effect results from two factors, each of which is important to the effect and each of which may be more prominent depending on the nature of the task: (a) perceptual mechanisms may always be present in the isolation effect, and they will be most evident in tasks where precategorical analysis of the information primarily determines performance on the task ${ }^{2}$; (b) differential rehearsal mechanisms will play a role when semantic features of the stimuli and the constraints of the task permit or demand utilization of higher-order memory processes.

\section{REFERENCES}

Cermak, L. S. Human memory: Research and theory. New York: Ronald, 1972.

Cimbalo, R. S. Short-term memory: The isolation effect with controlled output. Proceedings, 78th Annual Convention, APA, 1970, 5, 81-82.

Craik, F. I. M., \& Lockhart, R. S. Levels of processing: A framework for memory research. Journal of Verbal Learning \& Verbal Behavior, 1972, 11,671-684.

Crowder, R. G. Improved recall for digits with delayed recall cues. Journal of Experimental Psychology, 1969, 82, 258-262.

Crowder, R. G. Waiting for the stimulus suffix: Decay, delay, rhythm, and readout in immediate memory. Quarterly Journal of Experimental Psychology, 1971, 23, 324-340.

Crowder, R. G., \& Morton, J. Precategorical acoustic storage (PAS). Perception \& Psychophysics, 1969, 5, 365-373.

Crowder, R. G., \& Raeburn, V.P. The stimulus suffix effect with reversed speech. Journal of Verbal Learning \& Verbal Behavior, 1970, 9, 342-345.

Elmes, D. G., Sanders, L. W., \& Dovel, J. C. Isolation of massedand distributed-practice items. Memory \& Cognition, 1973, 1 , 77-79.

Massaro, D. W. Perceptual processes and forgetting in memory tasks. Psychological Review, 1970, 77, 557-567.

Moray, N. Listening and attention. Middlesex, England: Penguin, 1969.

Morton, J., Crowder, R. G., \& Prussin, H. A. Experiments with the stimulus suffix effect. Journal of Experimental Psychology, 1971, 91, 169-190.

Neisser, U. Cognitive psychology. New York: Appleton-Century-Crofts, 1967.

Norman, D. A. Memory and attention. New York: Wiley, 1969.

Wallace, W. P. Review of the historical, empirical, and theoretical status of the von Restorff phenomenon. Psychological Bulletin, 1965, 63, 410424.

Waugh, N. C. Free recall of conspicuous items. Journal of Verbal Learning \& Verbal Behavior, 1969, 8, 448-456.

\section{NOTES}

1. Sex of voice is confounded with the other manipulations. However, Morton et al (1971) have shown that it is voice quality that is of importance and not sex of voice per se.

2. The present argument is limited in the sense that it is based on studies that have used auditory presentation. It seems reasonable to expect a precategorical visual isolation effect, as the effects of "set" on performance in precategorical visual tasks suggest (Neisser, 1967).

(Received for publication July 13, 1973; revision received October $15,1973$. ) 